\title{
A Comparison of Winter Wheat Cultivar Rankings in Groups of Polish Locations
}

\author{
A. Derejko ${ }^{1}$, M. Studnicki ${ }^{1 *}$, W. MĄDrY ${ }^{1}$ and E. GACEK ${ }^{2}$ \\ ${ }^{1}$ Department of Experimental Design and Bioinformatics, Warsaw University of Life Sciences, \\ Nowoursynowska 159, 02-776 Warsaw, Poland \\ ${ }^{2}$ Research Centre for Cultivar Testing (COBORU), Słupia Wielka, Poland
}

(Received 15 October 2015; Accepted 1 April 2016;

Communicated by $\mathrm{H}$. Grausgruber)

\begin{abstract}
The grouping of locations from local-scale multi-environmental trials (METs) into megaenvironments has been criticized. Some European countries, e.g. the Czech Republic, Poland and Germany, have been characterized as possessing homogeneous environmental conditions. For aligned environmental conditions, it has been assumed that cultivar rankings will be similar and consequently cannot be used to designate mega-environments. An example of METs at the local scale is the Polish Post Registration Variety Testing System. The objective of this study was to determine groups of test sites within 16 Polish regions which are characterized by similar yield ranking of 50 winter wheat cultivars over three growing seasons (2011-2013). The compatibility of these cultivar yield rankings across regions was evaluated using Pearson correlation coefficients. Thereby, the 16 regions were divided into six groups (mega-environments) of locations. Regions within each group have similar cultivar rankings, whereas between groups, we observed different cultivar rankings, indicating crossover interactions. Besides similar cultivar yield responses the regions within megaenvironments were characterized also by similar environmental (soil and/or climate) condi-
\end{abstract} tions.

Keywords: adaptation, $\mathrm{G} \times \mathrm{E}$ interaction, mega-environment, multi-environmental trial, Triticum aestivum, yield

\section{Introduction}

Test sites can be grouped into so-called mega-environments according to two main approaches: (i) a priori identification of mega-environments based on a detailed description of environmental conditions of each location (e.g. geographic position, rainfall data, temperatures, soil type and fertility, farming system, etc.) (Annicchiarico et al. 2005; Barrero Farfan et al. 2013; Tapley et al. 2013); (ii) a posteriori identification of mega-environments based on the evaluation of the relative performance (differences of means or rankings) of investigated cultivars (Ebdon and Gauch 2002; Mandal et al. 2010; Munaro et al. 2014). Environments with similar (compatible) relative performance of cultivars are grouped into the same mega-environment (Mandal et al. 2010; Tapley et al. 2013).

*Corresponding author; E-mail: marcin_studnicki@sggw.pl; Phone: +48225932727 
Multi-environment trials (METs) allow researchers to investigate genotype by environment interactions $(\mathrm{G} \times \mathrm{E})$ and are performed at local, regional or global scales. Localscale METs are performed most frequently in a single country, regional-scale trials are performed across locations in one continent, and METs performed at a global scale include locations across many continents. Mega-environmental approaches are often used for regional and global METs, whereas the grouping of locations from local-scale METs into mega-environments has been criticized (Mühleisen et al. 2014). For example, some European countries (Czech Republic, Poland and Germany) have been characterized as possessing homogeneous environmental conditions. For aligned environmental conditions, it has been assumed that cultivar rankings will be similar and consequently cannot be used to designate mega-environments. An example of METs at the local scale is the Polish Post Registration Variety Testing System (PVTS), the purpose of which is the recommendation of cultivars to practice. This aim is achieved by creating lists of cultivars recommended for cultivation in a given (a priori designated) region being NUTS 2 (Nomenclature of Territorial Units for Statistics). These lists are based on the results of experiments conducted within the framework of the PVTS system in 16 regions across Poland. Previous PVTS studies have indicated diverse cultivar rankings in the trial locations (Mądry et al. 2013; Studnicki et al. 2015) and, thus, probably in the designated regions as well.

The objective of this study was to determine such groups within the 16 regions which are characterized by the similar yield ranking of 50 winter wheat cultivars over the locations in a regions and the three growing seasons from 2010/2011 to 2012/2013.

\section{Materials and Methods}

\section{Field trials}

The grain yield data used in this study represents a subset of the PVTS of winter wheat from three consecutive growing seasons (2011-2013). This dataset contains 50 modern winter wheat cultivars (Table 1) evaluated across 49 locations (Fig. 1). In total, $42 \%$ of the cultivars originated from Poland, whereas the rest of the cultivars were bred in Western European countries. The test sites were arranged into 16 regions (R) according to the highest-level administrative subdivisions (NUTS 2) of Poland. Each region contained at least two or at most five locations (Fig. 1).

The winter wheat cultivars in the PVTS were evaluated at two crop management intensities: (i) moderate-input management (MIM) and (ii) high-input management (HIM). MIM did not include plant protection treatments, and standard fertilization was applied according to the soil fertility of each location. HIM was a high-input treatment designed to maximize yield (i.e. high nitrogen fertilization, frequent use of fungicides, foliar fertilization, application of growth regulator). In this study, only data from HIM were used to reveal the full yield potential of the investigated cultivars.

The field experiments at each location and year were conducted in a two-factorial splitblock design with two replicates. Within blocks, the cultivars were laid out in sub-blocks, 


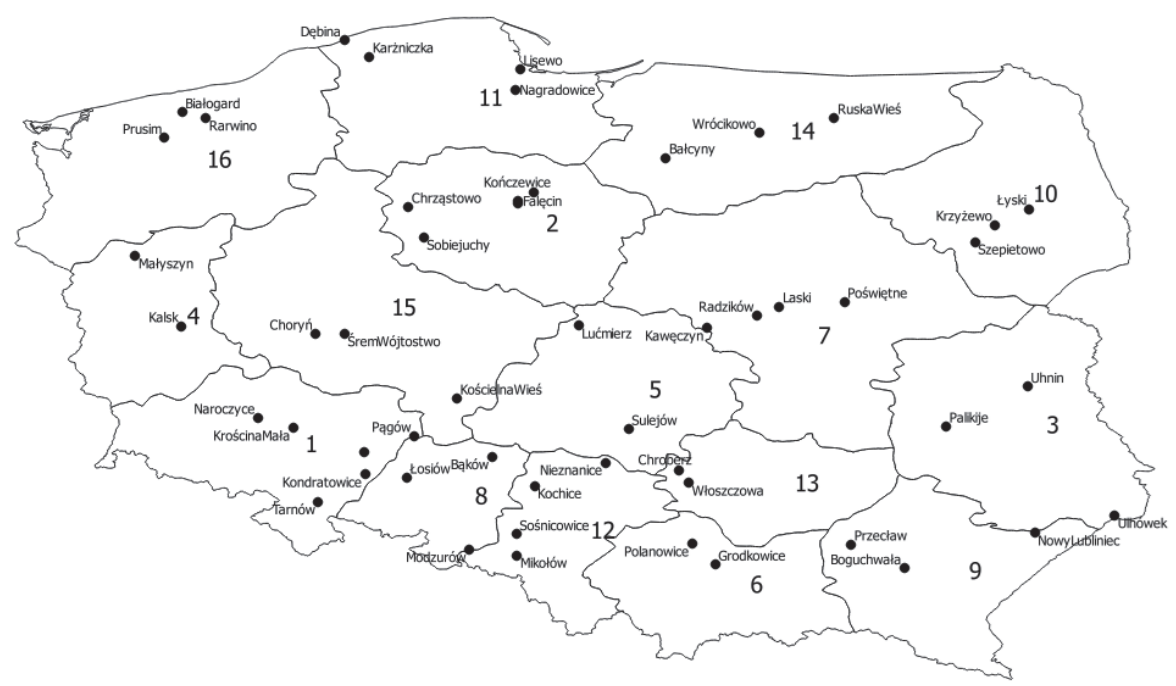

Figure 1. The 49 PVTS testing locations nested into 16 regions used to evaluate winter wheat cultivars under 16 regions across the 2010/2011 through 2012/2013 growing seasons. The number of regions on the map corresponding to number in Table 3

and the two crop managements in the other sub-blocks were arranged perpendicularly to the sub-blocks with the cultivars.

Ultimately, we obtained an incomplete GYL(R) (50 cultivars $G, 49$ locations nested into 16 regions $L(R), 3$ growing seasons $Y$ and 2 replications) dataset. Within this dataset, 5038 combinations (cells) were present, which represented $34.3 \%$ of the design. The incompleteness of the data resulted from different numbers of locations and/or years for the evaluated cultivars. The number of tested cultivars ranged from 17 to 41 in 2010/11, from 16 to 30 in 2011/12, and from 14 to 26 in 2012/13. The majority of cultivars were tested in all three years, seven cultivars were evaluated in only two growing seasons (Table S1*).

\section{Statistical analysis}

The statistical analysis was performed using a two-stage approach (Smith et al. 2005; Piepho et al. 2012). We assumed homogeneous residual error variances across locations and years. These assumptions are rather restrictive and may be unrealistic for many METs dataset (Möhring and Piepho 2009). Two-stage analyses with models without weighting produced acceptable results (Möhring and Piepho 2009). Although the unweighted twostage analysis will be approximated and can decrease the predictive accuracy in cultivar evaluation (Hu et al. 2013). Assuming of homogeneous residual error variances is very practical for large sets of four-way data within the linear mixed model. In the first stage,

*Further details about the Electronic Supplementary Material (ESM) can be found at the end of the article. 
the raw data (each location by year combination) were analysed using an ANOVA mixedmodel for split-block design (Federer and King 2007). For this analysis, we assumed that the cultivars and blocks were random effects. The least-squares (LS) means for cultivars were estimated and combined across locations nested in regions and year to obtain an unbalanced GYL(R) data table.

In the second stage of the combined analysis of the GYL(R) data, we used two different linear mixed models (LMM), each utilized for distinct purposes (Burgueño et al. 2011; Liu et al. 2013). First, an analysis of the LS means was conducted to test the significance of the effects of G, L(R), and Y and their interactions. Next, an analysis was performed based on the following model (Atlin et al. 2000; Studnicki et al. 2015):

$$
\begin{gathered}
\mathrm{X}_{i j k l}=\mu+\mathrm{Y}_{i}+\mathrm{R}_{l}+\mathrm{L}(\mathrm{R})_{j(l)}+\mathrm{YR}_{i l}+\mathrm{YL}(\mathrm{R})_{i j(l)}+\mathrm{G}_{k}+\mathrm{GY}_{i k}+\mathrm{GR}_{k l}+\mathrm{GL}(\mathrm{R})_{j k(l)}+ \\
+\mathrm{GYR}_{i k l}+\mathrm{GYL}(\mathrm{R})_{i j k(l)}
\end{gathered}
$$

where $\mathrm{X}_{i j k l}$ is the LS mean of the $k$ th cultivar at the $j$ th location in the $l$ th region and $i$ th year, $\mu$ the general mean, $\mathrm{Y}_{i}$ the random effect of the $i$ th year, $\mathrm{R}_{l}$ the fixed effect of the $l$ th region, $\mathrm{L}(\mathrm{R})_{j(l)}$ the fixed effect of the $j$ th location nested within the $l$ th region, $\mathrm{G}_{k}$ the random effect of the $k$ th cultivar, $\mathrm{YR}_{i l}$ the random effect of the $l$ th region in the $i$ th year, $\mathrm{YL}(\mathrm{R})_{i j(l)}$ the random effect of the $i$ th year by $j$ th location nested within the $l$ th region, $\mathrm{GY}_{i k}$ the random effect of the $k$ th cultivar by $i$ th year, $\mathrm{GR}_{k l}$ the random effect of the $k$ th cultivar by $l$ th region, GL(R $)_{j k(l)}$ the random effect of the $k$ th cultivar by $j$ th location nested within the $l$ th region, $\mathrm{GYR}_{i k l}$ the random effect of the $k$ th cultivar by $i$ th year by $l$ th region, and GYL(R) $)_{i j k(l)}$ the random effect of the $k$ th cultivar by $i$ th year by $j$ th location nested within the $l$ th region.

The significance of the fixed effects from model (1) was evaluated with the Wald $F$ test (Gilmour et al. 2009). The variance components for the random effects were estimated using the restricted maximum likelihood (REML) method (Patterson and Thompson 1971). The likelihood ratio test (LRT) was used to test the significance of the random effects. The LRT function test is given by $\mathrm{D}=2\left[\log \left(\mathrm{L}_{r 2}\right)-\log \left(\mathrm{L}_{r 1}\right)\right]$, where $\log \left(\mathrm{L}_{r 2}\right)$ is the $\log$ likelihood of model with the variance component and $\log \left(\mathrm{L}_{r 1}\right)$ is the $\log$ likelihood of model without the variance component (Wu and Matheson 2004; Gilmour et al. 2009).

In the second approach, an analysis of the GYL(R) LS means was conducted to estimate the adjusted means for the cultivar by region (GR) combination, based on a LMM with complex variance-covariance structure as follows:

$$
\mathrm{X}_{i j k l}=\mu+\mathrm{Y}_{i}+\mathrm{R}_{l}+\mathrm{L}(\mathrm{R})_{j(l)}+\mathrm{YR}_{i l}+\mathrm{YL}(\mathrm{R})_{i j(l)}+\mathrm{G}[\mathrm{L}(\mathrm{R})]_{k[j(l)]}+\mathrm{YG}[\mathrm{L}(\mathrm{R})]_{i k[j(l)]}
$$

where $\mathrm{G}[\mathrm{L}(\mathrm{R})]_{k[j(l)]}$ is the random effect of the $k$ th cultivar at the $j$ th location nested within the $l$ th region, GY[L(R) $]_{i k j(l)]}$ is the random interaction effect of the $k$ th cultivar and $i$ th year at the $j$ th location nested within the $l$ th region, and the other abbreviations are defined as in model (1).

For the random effects of the cultivars at locations $\mathrm{G}[\mathrm{L}(\mathrm{R})]_{k[j(l)]}$ in model (2), we assumed a factor analytic structure with two components, FA(2), for the genetic variance- 
covariance matrix (Smith et al. 2001; Kelly et al. 2007). The best linear unbiased estimators (BLUEs) for the fixed effects and the best linear unbiased predictors (BLUPs) of the random effects in model (2) were utilized to calculate adjusted GR means on average locations using the algorithm described by Welham et al. (2004). The obtained adjusted means were used to determine the cultivar rankings in each region on average locations. Therefore, the compatibility of these cultivar yield rankings across regions was evaluated using Pearson correlation coefficients. Pairs of regions with positive and high values were characterized by highly compatible cultivar rankings. To group regions with similar cultivar rankings by cluster analysis, we used Ward's agglomeration method. The dissimilarity measure for clustering was defined as $1-r$ (Pearson correlation coefficient). The final number of regional groups was determined by a ratio that described the portion of the total between-region variation that was explained by the cluster analysis (Seber 2004). The dendrogram was cut when the fusion of groups performed at this ratio level approached $70 \%$.

For this analysis we used a R 3.2.1 software package. The applied LMM were fitted using ASReml 3.0, implemented in the R software package ASReml-R (Gilmour et al. 2009).

\section{Results}

Significant fixed effects were observed for regions $R$ (Table 2) in model (1), which indicated a significant difference in mean grain yields between the 16 regions. The yield means varied from $8.30 \mathrm{t} \mathrm{ha}^{-1}$ in Małopolskie to $14.83 \mathrm{t} \mathrm{ha}^{-1}$ in Wielkopolskie (Table 3). The Wald $F$ test also indicated a statistically significant main effect for $L(R)$. Variance components for cultivars $G$ were significantly different from zero, but explained only $0.3 \%$ of the total variation. Cultivar yields ranged from $10.80 \mathrm{dt} \mathrm{ha}^{-1}$ for Naridana to $11.88 \mathrm{dt} \mathrm{ha}^{-1}$ for Linus (Table 1). Random environmental effects $[Y, Y R, Y L(R)]$ jointly explained $89.29 \%$ of the total variance components (Table 2). The size of the $Y L(R)$ and $Y R$ interactions variance equalled or exceeded that of the other components and constituted a major part of the variation in grain yield. Moreover, we found statistically significant $G R$ and $G L(R)$ interactions. This result indicates that the rankings of the 50 cultivars tested across the 16 regions were not the same. The highest and most positive correlation coefficient (Table S2) observed between regions was for Pomorskie and Dolnośląskie $(r=0.91)$, revealing a compatible ranking of cultivars across these regions. Furthermore, high, positive correlation coefficients were also observed for Śląskie and Mazowieckie $(r=0.85)$, Dolnośląskie and Zachodnio-Pomorskie $(r=0.81)$, Lubuskie and Dolnośląskie $(r=0.88)$, and Kujawsko-Pomorskie and Lubuskie $(r=0.85)$. Between some regions a negative correlation coefficients were observed, e.g. between Śląskie and Podlaskie $(r=-0.48)$ and between Opolskie and Pomorskie $(r=-0.35)$. A negative correlation between regions means that the highest-yielding cultivars in one region were the lowestyielding ones in the other region. A correlation close to zero means that there is no consensus ranking of the cultivars between regions. Correlation coefficients close to zero 
Table 1. Mean grain yield of the 50 tested winter wheat cultivars from 49 locations nested in 16 groups across 3 growing seasons

\begin{tabular}{|c|c|c|}
\hline Cultivars & $\begin{array}{l}\text { Grain yield } \\
\left(\mathrm{t} \mathrm{ha}^{-1}\right)\end{array}$ & $\begin{array}{l}\text { Standard error of } \\
\text { grain yield means }\end{array}$ \\
\hline Akteur & 11.22 & 0.83 \\
\hline Alves & 11.48 & 0.86 \\
\hline Arkadia & 11.63 & 0.82 \\
\hline Askalon & 11.58 & 0.87 \\
\hline Bagou & 11.17 & 0.87 \\
\hline Baletka & 11.47 & 0.88 \\
\hline Bamberka & 11.34 & 0.80 \\
\hline Banderola & 11.36 & 0.83 \\
\hline Batuta & 11.43 & 0.89 \\
\hline Belenus & 11.31 & 0.83 \\
\hline Bockris & 11.27 & 0.80 \\
\hline Bogatka & 11.11 & 0.84 \\
\hline Boomer & 11.54 & 0.86 \\
\hline Brilliant & 11.26 & 0.90 \\
\hline Bystra & 11.06 & 0.84 \\
\hline Fidelius & 11.57 & 0.82 \\
\hline Figura & 11.37 & 0.80 \\
\hline Forkida & 11.02 & 0.84 \\
\hline Galvano & 11.40 & 0.91 \\
\hline Henrik & 11.61 & 0.84 \\
\hline Jantarka & 11.52 & 0.81 \\
\hline Jenga & 11.33 & 0.82 \\
\hline Julius & 11.65 & 0.90 \\
\hline Kampana & 11.10 & 0.84 \\
\hline Kepler & 11.52 & 0.83 \\
\hline
\end{tabular}

\begin{tabular}{|l|c|c|}
\hline \multicolumn{1}{|c|}{ Cultivars } & $\begin{array}{c}\text { Grain yield } \\
\left(\mathrm{t} \mathrm{ha}^{-1}\right)\end{array}$ & $\begin{array}{c}\text { Standard error of } \\
\text { grain yield means }\end{array}$ \\
\hline Kohelia & 10.94 & 0.84 \\
\hline Kranich & 11.22 & 0.84 \\
\hline Kredo & 11.33 & 0.88 \\
\hline Legenda & 11.62 & 0.87 \\
\hline Linus & 11.88 & 0.84 \\
\hline Look & 11.46 & 0.88 \\
\hline Markiza & 11.02 & 0.84 \\
\hline Meteor & 11.69 & 0.87 \\
\hline Mulan & 11.53 & 0.82 \\
\hline Muszelka & 11.35 & 0.80 \\
\hline Naridana & 10.80 & 0.85 \\
\hline Nateja & 11.03 & 0.86 \\
\hline Natula & 11.34 & 0.81 \\
\hline Operetka & 11.41 & 0.88 \\
\hline Ostroga & 11.40 & 0.82 \\
\hline Oxal & 11.26 & 0.85 \\
\hline Pamier & 11.63 & 0.91 \\
\hline Rapsodia & 11.21 & 0.92 \\
\hline Sailor & 11.65 & 0.82 \\
\hline Skagen & 11.55 & 0.81 \\
\hline Smaragd & 11.44 & 0.88 \\
\hline Smuga & 11.29 & 0.87 \\
\hline Tonacja & 17 \\
\hline Torrild & 1.89 \\
\hline Wydma & 11.82 \\
\hline
\end{tabular}

Overall mean $=11.36 \mathrm{t} \mathrm{ha}^{-1} ; \mathrm{SED}($ standard error of differences $)=0.94$.

were observed between Warmińsko-Mazurskie and Opolskie $(r=0.01)$ and between Podlaskie and Wielkopolskie $(r=-0.02)$.

A division of the 16 regions into six groups is justified by the dendrogram (Fig. 2), which shows the level of similarity at all agglomeration steps. For this number of clusters, $73 \%$ of the overall variation among the regions was explained. Regions within each group have compatible cultivar rankings, whereas between groups, we observed different culti- 
Table 2. Variance components in the per cent of total variation for random effects and the Wald $\mathrm{F}$ ratio for fixed effects in a linear mixed model (model 1) in the winter wheat PVST dataset under HIM crop management system

\begin{tabular}{|l|c|c|c|c|}
\hline \multirow{2}{*}{ Factor } & \multicolumn{2}{|c|}{ Variance components } & \multicolumn{2}{c|}{ Wald $\mathrm{F}$} \\
\cline { 2 - 5 } & $\%$ & $p$ value & Test statistic & $p$ value \\
\hline Year $(Y)$ & 0.13 & 0.0012 & & \\
\hline Year $\times$ Region $(Y R)$ & 25.46 & 0.0358 & & \\
\hline Year $\times$ Location(Region) $(Y L(R))$ & 63.70 & 0.0001 & & \\
\hline Cultivar $(G)$ & 0.30 & 0.0071 & & \\
\hline Cultivar $\times$ Year $(G Y)$ & 6.14 & 0.0015 & & \\
\hline Cultivar $\times$ Region $(G R)$ & 0.34 & 0.0261 & & \\
\hline Cultivar $\times$ Location $($ Region $)(G L(R))$ & 0.45 & 0.0178 & & \\
\hline Cultivar $\times$ Year $\times$ Region $(G Y R)$ & 3.18 & 0.0047 & & \\
\hline Cultivar $\times$ Year $\times$ Location $($ Region $)(G Y L(R))$ & 0.30 & 0.0085 & & \\
\hline Region $(R)$ & & & 38.33 & 0.0025 \\
\hline Location $($ Region $)(L(R))$ & & & 141.34 & 0.0047 \\
\hline
\end{tabular}

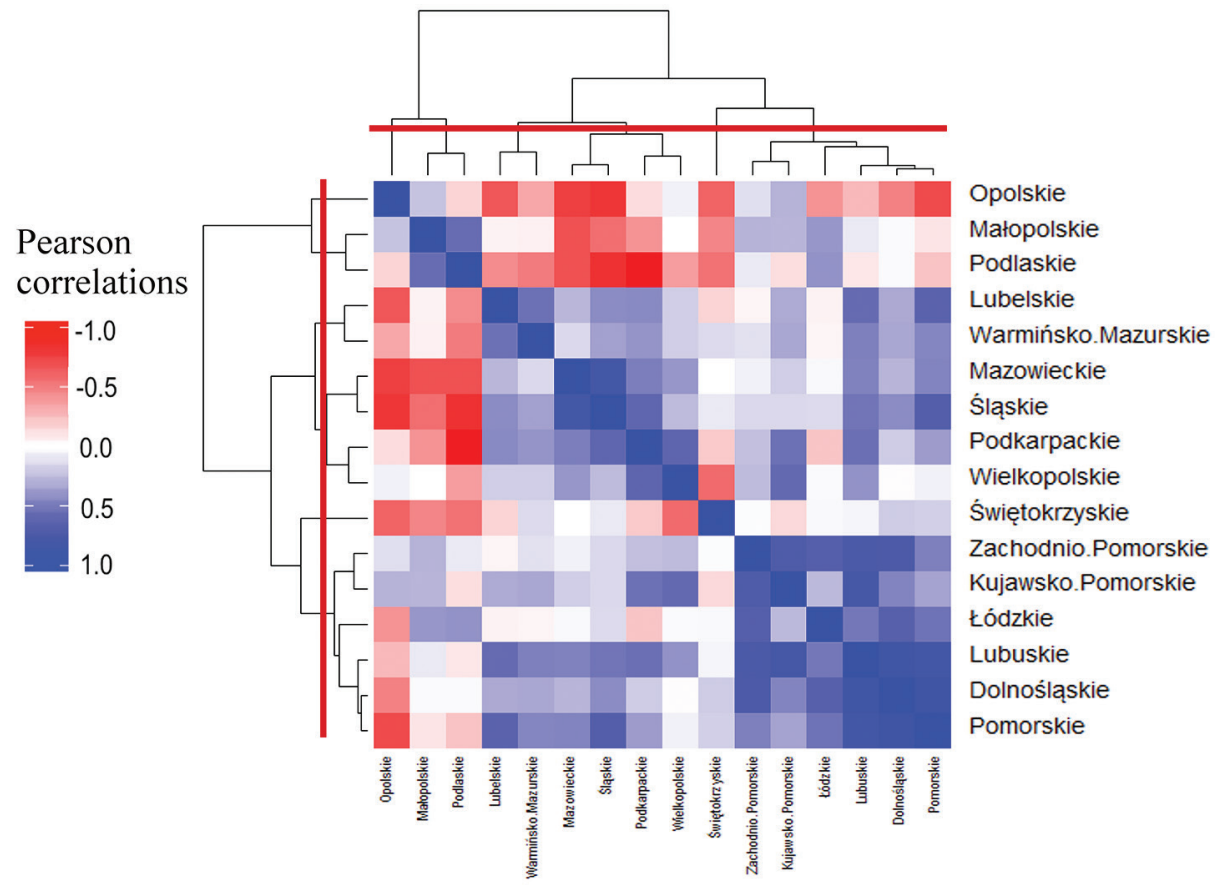

Figure 2. Dendrogram and correlation plot (heat map) of the 16 regions based on similar cultivar rankings. The red lines indicates a cut-off point in to 6 groups of regions 
Table 3. Mean grain yields in the regions averaged from 50 cultivars and across 3 growing seasons

\begin{tabular}{|l|c|c|}
\hline \multicolumn{1}{|c|}{ Regions } & Grain yield $\left(\mathrm{t} \mathrm{ha}^{-1}\right)$ & $\begin{array}{c}\text { Standard error of } \\
\text { grain yield means }\end{array}$ \\
\hline Dolnośląskie (1) & 10.66 & 0.79 \\
\hline Kujawsko-Pomorskie (2) & 12.22 & 0.91 \\
\hline Lubelskie (3) & 10.45 & 0.84 \\
\hline Lubuskie (4) & 11.18 & 0.81 \\
\hline Łódzkie (5) & 10.06 & 1.10 \\
\hline Małopolskie (6) & 8.30 & 1.14 \\
\hline Mazowieckie (7) & 10.49 & 0.96 \\
\hline Opolskie (8) & 13.62 & 0.99 \\
\hline Podkarpackie (9) & 12.49 & 0.81 \\
\hline Podlaskie (10) & 13.14 & 0.79 \\
\hline Pomorskie (11) & 10.92 & 1.01 \\
\hline Śląskie (12) & 10.92 & 0.78 \\
\hline Świętokrzyskie (13) & 8.92 & 0.98 \\
\hline Warmińsko-Mazurskie (14) & 13.77 & 0.85 \\
\hline Wielkopolskie (15) & 14.83 & 0.98 \\
\hline Zachodnio-Pomorskie (16) & 9.71 & 0.94 \\
\hline
\end{tabular}

Overall mean $=11.36 \mathrm{tha}^{-1} ; \mathrm{SED}($ standard error of differences $)=1.52$.

var rankings, indicating crossover interactions (COIs) between regional groups. Group 1 consisted of only one region, Opolskie, which produced one of the highest average yields (Table 3). Opolskie region, is characterized by a short winter, an early spring and a long, mild autumn, and is one of the best Polish regions for plant production. The land is lowlying, flat, and slightly undulating, and the region is one of the warmest in Poland. Opolskie region displayed negative correlations with most of the other regions (Table 4). Group 2 contained the Podlaskie and Małopolskie regions, which exhibited highly diverse average yields (Podlaskie: $13.14 \mathrm{t} \mathrm{ha}^{-1}$; Małopolskie: $8.30 \mathrm{t} \mathrm{ha}^{-1}$ ). Regions within group 2 exhibited low positive correlations and many negative correlations with other regions. Two regions (Warmińsko-Mazurskie and Lubuskie) belonged to group 3. Group 4 included Mazowieckie, Śląskie, Podkarpackie and Wielkopolskie. Group 5 contained only Świętokrzyskie region, which was a low-yielding environment (8.92 t ha $\left.\mathrm{h}^{-1}\right)$. Group 6 included six regions, i.e. Zachodnio-Pomorskie, Kujawsko-Pomorskie, Łódzkie, Lubelskie, Dolnośląskie and Pomorskie. The climates of the Zachodnio-Pomorskie and Pomorskie regions are due to the overlapping maritime and inland influences in the area. A similar climatic variability exists in the Łódzkie region, although humidity and precipitation is low. Between the groups of regions, we observed correlation coefficients close to zero or values well below the adopted criteria, reflecting the lack of compatible cultivar rankings between the groups. Thus, the regional groups exhibited different cultivar rankings. 


\section{Discussion}

The grain yield of winter wheat from the PVTS under HIM was strongly influenced by environmental effects (locations nested in regions, years). This result was similar to studies in which environmental effects were shown to be responsible for approximately $80 \%$ or more of the total experimental variation in wheat grain yield (Atlin and McRae 1994; Mohammadi et al. 2010; Tapley et al. 2013). Gauch and Zobel (1997) reported that locations accounted for approximately $80 \%$ of total variation, whereas genotype and $\mathrm{G} \times \mathrm{E}$ interactions each accounted for approximately $10 \%$. In our study, relatively high values of variance components for the environmental effects $(Y R$ and $Y L(R))$ confirmed that agro-ecological conditions in the trial locations varied, which caused most of the yield variation in the winter wheat PVTS. G $\times E$ interactions is third highest $(6.1 \%)$ for the interaction with the year, and $3.2 \%$ can be contributed to GYR. There is a big difference in variation explained by $\mathrm{YL}(\mathrm{R})-63.70 \%$ and $\mathrm{YR}-25.46 \%$ compared to interactions including $\mathrm{G}-0.30 \%$. Thus, this result show that environmental effects and their interactions are very important for selection and ranking wheat cultivars. Therefore, the 50 test cultivars reacted differently to the environmental conditions of each test location.

We observed strongly differing mean yields and cultivar rankings between the regions. Despite the relatively homogeneous climatic and environmental conditions in Poland and their correspondingly aligned environmental conditions, we observed a strong impact of environmental effects on the variation in grain yields. The relative homogeneity of the environmental conditions is apparent, despite similar (limited) climatic zones and latitudes. Therefore, the determination of mega-environments is reasonable for these localscale METs. The regions included in each respective group were characterized by similar cultivar responses towards environmental conditions. Although Mühleisen et al. (2014) criticized the creation of mega-environments in this region, our study does not support their hypothesis.

The winter wheat PVST experiments for the study of $G R$ interactions present a particular advantage: all or almost all of the cultivars exhibit a narrow pattern of specific adaptations to local conditions due to the small, local and isolated breeding efforts applied to this species, which result in contrasting relative responses across a relatively narrow range of environments. One possibility for the lower magnitude of the $G R$ interaction observed in our study was the use of a comparison of cultivar compatibility rankings in groups of locations (mega-environments). $G R$ interactions were significant, although they represented only $0.39 \%$ of the total variation. However, our study uncovered different cultivar rankings, indicating the considerable influence of crossover interactions. The similarity of cultivar rankings in some regions allows a reduction in the number of test locations. The consequent lowering in costs can be significant, and it is well recognized that there is an opportunity cost for additional locations (Atlin and McRae 1994). There is also a need for compliance at a global level for comparison rankings of all cultivars included in a region. The yield rankings are the basis of regional recommendations of cultivars. 
The present 16 regions were divided into six groups of test locations. Isolating groups of locations with similar cultivar rankings may lower the number of experiments needed. The regions included within a specific group were characterized by similar cultivar responses and similar environmental conditions (long-term climate data was presented in Table S3 in supplements material). Group 1 contained a region (Opolskie) that is characterized by the most favourable soil and climate conditions for growing winter wheat in Poland. The regions included in group 2 have a cold winter. In this region, cultivar rankings were strongly determined by the frost tolerance of the winter wheat cultivars. Regions with very similar climatic conditions were included in group 3, but these regions are characterized by favourable soil conditions for growing winter wheat. Group 4 included four regions with average soil conditions but optimal water availability for wheat cultivation. The single region classified in group 5, Świętokrzyskie, contains the most adverse soil and climate conditions. The regions of group 6 are characterized by water stress; these regions have the lowest below-average annual rainfall in Poland. The groups of regions can thus be considered to constitute a identification of mega-environments. The mega-environment were characterized by similar soil and/or climate conditions. Delineating these mega-environments will increase the effectiveness of METs and cultivar recommendations.

\section{References}

Annicchiarico, P., Bellah, F., Chiari, T. 2005. Defining subregions and estimating benefits for a specific-adaptation strategy by breeding programs: A case study. Crop Sci. 45:1741-1749.

Atlin, G.N., Baker, R.J., McRae, K.B., Lu, X. 2000. Selection response in subdivided target regions. Crop Sci. 40:7-13.

Atlin, G.N., McRae, K.B. 1994. Resource allocation in Maritime cereal cultivar trials. Can. J. Plant Sci. 74:501-505.

Burgueño, J., Crossa, J., Cotes, J.M., Vicente, F.S., Das, B. 2011. Prediction assessment of linear mixed models for multi-environment trials. Crop Sci. 51:944-954.

Barrero Farfan, I.D., Murray, S.C., Labar, S., Pietsch, D. 2013. A multi-environment trial analysis shows slight grain yield improvement in Texas commercial maize. Field Crop Res. 149:167-176.

Ebdon, J.S., Gauch, H.G. 2002. Additive main effect and multiplicative interactions analysis of national turfgrass performance trials. Interpretation of genotype $\times$ environment interactions. Crop Sci. 42:489-496.

Federer, W.T., King, F. 2007. Variations on Split Plot and Split Block Experiment Designs. John Wiley and Sons. New York, USA.

Gauch, H.G., Zobel, R.W. 1997. Identifying mega-environments and targeting genotypes. Crop Sci. 37:311326.

Gilmour, A.R., Gogel, B.J., Cullis, B.R., Thompson, R. 2009. ASReml User Guide Release 3.0. VSN International Ltd., Hemel Hempstead, UK.

Hu, X., Yan, S., Shen, K. 2013. Heterogeneity of error variance and its influence on genotype comparison in multi-location trials. Field Crop Res. 149:322-328.

Kelly, A.M., Smith, A.B., Eccleston, J.A., Cullis, B.R. 2007. The accuracy of varietal selection using factor analytic models for multi-environment plant breeding trials. Crop Sci. 47:1063-1070.

Liu, S.M., Constable, G.A., Reid, P.E., Stiller, W.N., Cullis, B.R. 2013. The interaction between breeding and crop management in improved cotton yield. Field Crop Res. 148:49-60.

Mądry, W., Paderwski, J., Gozdowski, D., Rozbici, J., Golba, J., Piechociński, M., Studnicki, M., Derejko, A. 2013. Adaptation of winter wheat cultivars to crop managements and Polish agricultural environments. Turkish J. Field Crop 18:118-127. 
Mandal, N.P., Sinha, P.K., Variar, M., Shukla, V.D., Perraju, P., Mehta, A., Pathak, A.R., Dwivedi, J.L., Rathi, S.P.S., Bhandarkar, S., Singh, B.N., Singh, D.N., Panda, S., Mishra, N.C., Singh, Y.V., Pandya, R. 2010. Implications of genotype $\times$ input interactions in breeding superior genotypes for favourable and unfavourable rainfed upland environments. Field Crop Res. 118:135-144.

Mohammadi, R., Roustaii, M., Haghparast, R., Roohi, E., Solimani, K., Ahmadi, M., Abedi, R., Amri, A. 2010. Genotype $\times$ environment interactions for grain yield in rainfed winter multi-environment trials in Iran. Agron. J. 102:1500-1510.

Möhring, J., Piepho, H.P. 2009. Comparison of weighting in two-stage analyses of series of experiments. Crop Sci. 49:1977-1988.

Munaro, L.B., Benin, G., Marchioro, V.S., de Assis Franco, F., Silva, R.R., de Silva, C.L., Beche, E. 2014. Brazilian spring wheat homogeneous adaptation regions can be dissected in major mega-environments. Crop Sci. 54:1374-1383.

Mühleisen, J., Piepho, H.P., Maurer, H.P., Zhao, Y., Reif, J.C. 2014. Exploitation of yield stability in barley. Theor. Appl. Genet. 127:1949-1962.

Patterson, H.D., Thompson, R. 1971. Recovery of inter-block information when block sizes are unequal. Biometrika 58:545-554.

Piepho, H.P., Möhring, J., Schulz-Streeck, T., Ogutu, J.O. 2012. A stage-wise approach for analysis of multienvironment trials. Biom. J. 54:844-860.

Seber, G.A.F. 2004. Multivariate Observations. John Wiley and Sons. New York, USA.

Smith, A.B., Cullis, B.R., Thompson, R. 2001. Analyzing variety by environment data using multiplicative mixed models and adjustments for spatial field trend. Biometrics 57:1138-1147.

Smith, A.B., Cullis, B.R., Thompson, R. 2005. The analysis of crop cultivar breeding and evaluation trials: an overview of current mixed model approaches. J. Agric. Sci. 143:449-462.

Studnicki, M., Mądry, W., Derejko, A., Noras, K., Wójcik-Gront, E. 2015. Four-way data analysis within the linear mixed modelling framework. Sci. Agric. 72:411-419.

Tapley, M., Ortiz, B.V., van Santen, E., Balkcom, K.S., Mask, P., Weaver, D.B. 2013. Location, seeding date, and variety interactions on winter wheat yield in South-eastern United States. Agron. J. 105:509-518.

Welham, S.J., Cullis, B.R., Gogel, B.J., Gilmour, A.R., Thompson, R. 2004. Prediction in linear mixed models. Aust. NZ. J. Stat. 46:325-347.

Wu, H.X., Matheson, A.C. 2004. General and specific combining ability from partial diallels of radiata pine: implications for utility of SCA inbreeding and deployment populations. Theor. Appl. Genet. 108:15031512 .

\section{Electronic Supplementary Material (ESM)}

Electronic Supplementary Material (ESM) associated with this article can be found at the website of CRC at http://www.akademiai.com/content/120427/

Electronic Supplementary Table S1. The number of trial locations for winter wheat cultivars in the Polish PVTS across the growing seasons of 2010/2011 through 2012/2013

Electronic Supplementary Table S2. Similarity of winter wheat cultivar rankings across 16 regions according to Pearson correlation coefficients

Electronic Supplementary Table S3. The annual rainfall and average temperature for long-term data 